\title{
TECHNOLOGY FOR OIL ENRICHED BY POLYUNSATURATED FATTY ACIDS
}

\author{
ТЕХНОЛОГИЯ МАСЛА ОБОГАЩЕННОГО ПОЛИНЕНАСЫЩЕННЫМИ \\ ЖИРНЫМИ КИСЛОТАМИ
}

\section{K. Leshukov, Candidate of Biological Sciences}

К.А. Лещуков, кандидат биологических наук

K. Klimov, O. Kuprina, Post-graduate students

К.Е. Климов, О.А. Куприна, аспиранты

Orel State Agrarian University, Orel City, Russia

Орловский государственный аграрный университет, г. Орёл, Россия

Phone: +7 (920) 803-50-40, E-mail: kost177@mail.ru

Received February 27, 2012

\begin{abstract}
The technology of butter with the "OmegaTrin" complex with the balanced content of polynonsaturated fat acids is developed. Studied the fatty acid composition of milk - raw materials, optimal amount of insertion of polyunsaturated fatty acids, organoleptic characteristics of enriched butter; studied physico-chemical properties and biological value (biological effectiveness) of the final product, fatty acid composition of a new product, set the shelf life and developed an oil recipe.
\end{abstract}

\section{АННОТАЦИЯ}

Разработана технология сливочного масла с комплексом «ОмегаТрин» со сбалансированным содержанием полиненасыщенных жирных кислот. Изучены жирнокислотный состав молока сырья; подобрано оптимальное количество вносимых полиненасыщенных жирных кислот; оченены органолептические показатели обогащенного сливочного масла; изучены физикохимические показатели и биологическая ценность (биологическая эффективность) готового продукта; жирнокислотный состав нового продукта; установлены сроки хранения и разработана рецептура масла.

\section{KEY WORDS}

Butter; Complex «OmegaTrin»; Fatty acids; Physico-chemical parameters; Biological value.

\section{КЛЮЧЕВЫЕ СЛОВА}

Сливочное масло; Комплекс «ОмегаТрин»; Жирные кислоты; Физико-химические показатели; Биологическая ценнноть.

В общественном сознании в последнее время все прочнее укрепляется тенденция здорового образа жизни и соблюдение принципов сбалансированного полноценного питания. При выявлении в структуре питания населения дисбаланса по основным компонентам возникает необходимость поиска их решения. Методические возможности и современные системы интерпретации исследований позволяют изменить подход к исполь- зованию традиционных продуктов питания растительного и животного происхождения.

Сливочное масло в большей степени служит источником насыщенных жирных кислот $(53 \ldots 77 \%)$, чем ненасыщенных $(25 \ldots 47 \%)$, содержание полиненасыщенных кислот совсем незначительно. Поэтому жирнокислотный состав молочного жира из дополнительного показателя качества жиров превращается в одну из основных характеристик. 
Исследования, проведенные в ведущих научно-исследовательских учреждениях страны, показывают, какую огромную роль в жизнедеятель-ности организма человека играют полиненасыщенные жирные кислоты (ПНЖК). Являясь физиологически активными веществами, они принимают активное участие в обменных процессах, являются факторами роста, обладают антисклеротическим действием, участвуют в обеспечении нормаль-ного углеводно-жирового обмена, регулировании окислительно-восстановительных процессов, нормализации холестеринового обмена. Особенно важными в этом смысле являются глицериды жиров, содержа-щие линолевую ( $\omega-3)$, линоленовую $(\omega-6)$ и арахидоновую ( $\omega-9)$ жирные кислоты, которые называются эссенциальными. При недостатке этих ки-слот в организме человека холестерин образует с насыщенными жирными кислотами сложные эфиры, трудно расщепляющиеся при обмене веществ [2].

Следует отметить, что в масле из коровьего молока содержится недостаточное количество ПНЖК. Ни одно из вырабатываемых в настоящее время сливочных масел не имеет необходимого соотношения насыщенных (НЖК), мононенасыщенных (МНЖК) и полиненасыщенных (ПНЖК) жир-ных кислот.

В этой связи, целью исследований является разработка технологии производства сливочного масла со сбалансированным жирнокислотным составом, путем введение в рецептуру композиции «ОмегаТрин».

Исходя из общей цели, решались следующие задачи: изучить жирно-кислотный состав молока - сырья; подобрать оптимальное количество вно-симых ПНЖК для обогащения сливочного масла; дать оценку органолеп-тическим показателям обогащенного сливочного масла; изучить влияние ПНЖК на изменения физико-химических показателей и биологическую ценность (биологическую эффективность) готового продукта; изучить жирнокислотный состав нового продукта; установить сроки хранения.

Исследования проводились в инновационном научно-исследовательском испытательном центре ФГБОУ ВПО «Орловский государственный аграрный университет» (№ гос. аккредитации POCC RU.0001.21ПЦ26 от 06.06.2011 г.) и Всероссийском научноисследовательском институте физиологии, биохимии и питания Россельхозакадемии.

Массовую долю жира, белка, влаги, СОМО, плотность молока и температуру замерзания измеряли с помощью прибора «Лактан 1-4». Определение количества и величины жировых шариков молока определяли с помощью камеры Горяева. Содержание жирных кислот определяли хроматографическим методом. Сливочное масло вырабатывали способом сбивания сливок согласно требованиям «Технического регламента на молоко и молочную продукцию» № 88- Ф3 и ГОСТ Р 52969-2008. Непосредственно перед процессом сбивания сливок в них вносят комплекс полиненасыщенных жирных кислот «Омега Трин», предварительно растворенного в небольшом количестве сливок при температуре $35-40^{\circ} \mathrm{C}$, затем смесь тщательно перемешивается.

Таблица 1 - Состав опытных образцов

\begin{tabular}{|c|c|c|c|}
\hline Наименование сырья & \multicolumn{3}{|c|}{ Масса компонентов, г } \\
\hline Сливки пастеризованные, мдж 35\% & Образец 1 & Образец 2 & $\begin{array}{c}\text { Контрольный } \\
\text { образец }\end{array}$ \\
\hline Комплекс «ОмегаТрин»» в количестве: & 1000 & 1000 & 1000 \\
\hline Итого & 0,780 & 1,560 & - \\
\hline- & 1000,780 & 1001,560 & 1000 \\
\hline
\end{tabular}

Качество вырабатываемого масла в значительной степени зависит от качества сырья. Основным сырьём для производства сливочного масла являются сливки, которые получают при сепарировании молока.

Согласно проведенным исследованиям по изучению качества молока установлено, что молоко полностью соответствует требованиям, предъявляемым к молоку-сырью для производства сливочного масла указанным в «Техническом регламенте на молоко и молочные продукты» (12 июня 2008 года ФЗ № 88). Степень использования жира зависит от размера жировых шариков, поэтому были проведены 
исследования по измерению размера жировых шариков молока. В исследуемом молоке преобладали жировые шарики с размером 2,5-3 мкм, что оптимально подходит для производства сливочного масла.

Из всех природных жиров молочный по химическому составу является самым слож- ным и уникальным. Особенность жирнокислотного состава молочного жира - наличие низкомолекулярных короткоцепочечных жирных кислот (ЖК). Жиры немолочного происхождения в основном состоят из высокомолекулярных ЖК. Жирнокислотный состав исследуемого молока приведен в таблице 2.

Таблица 2 - Показатели качества используемого молока-сырья, $(\mathrm{M} \square \mathrm{m}), \mathrm{n}=3$

\begin{tabular}{|c|c|c|c|c|c|c|}
\hline $\begin{array}{c}\text { Показа- } \\
\text { тель }\end{array}$ & $\begin{array}{c}\text { Массовая доля } \\
\text { жра, \% }\end{array}$ & $\begin{array}{c}\text { Плотность, } \\
\mathrm{A}\end{array}$ & $\mathrm{COMO}$ & $\begin{array}{c}\text { Вода, } \\
\%\end{array}$ & $\begin{array}{c}\text { Массовая доля } \\
\text { белка, \% }\end{array}$ & $\begin{array}{c}\text { Температура замерза- } \\
\text { ния, }{ }^{\circ} \mathrm{C}\end{array}$ \\
\hdashline Молоко & $4,2 \pm 0,38$ & 27 & $8,4 \pm 1,06$ & 0 & $3,4 \pm 0,42$ & $0,512 \pm 0,07$ \\
\hdashline
\end{tabular}

Из таблицы видно, что жирнокислотный состав исследуемого молока для производства сливочного масла соответствует нормам по содержанию жирных кислот в молоке [1]. При рассмотрении жирнокислотного состава липидов молока, представленного в таблице, следует, прежде всего, отметить, что основ- ную массовую долю их составляют кислоты с длинной углеродной цепи 16 и 18 атомов. На долю С18 приходится около 23\%, общего количества кислот. Наибольшим количеством $(35,19 \%)$ из всех жирных кислот обладает пальмитиновая кислота (С16).

Таблица 3 - Жирнокислотный состав исследуемого молока, $(\mathrm{M} \pm \mathrm{m})$

\begin{tabular}{|c|c|c|c|}
\hline \multicolumn{2}{|c|}{ Наименование жирных кислот } & \multirow{2}{*}{$\begin{array}{c}\text { Число атомов углерода и } \\
\text { принятое обозначение }\end{array}$} & \multirow{2}{*}{$\begin{array}{l}\text { Массовая доля в мо- } \\
\text { лочном жире, \% }\end{array}$} \\
\hline Тривиальное & Систематическое & & \\
\hline Каприловая & п-Октановая & $\mathrm{C}_{7} \mathrm{H}_{15} \mathrm{COOH}$ & $3,30 \pm 0,35$ \\
\hline Каприновая & п-Декановая & $\mathrm{C}_{9} \mathrm{H}_{19} \mathrm{COOH}$ & $1,45 \pm 0,21$ \\
\hline Лауриновая & п-Додекановая & $\mathrm{C}_{11} \mathrm{H}_{23} \mathrm{COOH}$ & $3,7 \pm 0,53$ \\
\hline Миристиновая & п-Тетрадекановая & $\mathrm{C}_{13} \mathrm{H}_{27} \mathrm{COOH}$ & $12,25 \pm 1,57$ \\
\hline Пальмитиновая & п-Гексадекановая & $\mathrm{C}_{15} \mathrm{H}_{31} \mathrm{COOH}$ & $35,19 \pm 4,61$ \\
\hline Стеариновая & п-Октадекановая & $\mathrm{C}_{17} \mathrm{H}_{35} \mathrm{COOH}$ & $9,80 \pm 1,24$ \\
\hline Миристолеиновая & 9-Тетрадеценовая & $\mathrm{C}_{13} \mathrm{H}_{25} \mathrm{COOH}$ & $2,84 \pm 0,35$ \\
\hline Линолевая & 9, 12-0ктадекадиеновая & $\mathrm{C}_{17} \mathrm{H}_{31} \mathrm{COOH}$ & $3,64 \pm 0,39$ \\
\hline Линоленовая & 9,12,15-0ксидекатриеновая & $\mathrm{C}_{17} \mathrm{H}_{29} \mathrm{COOH}$ & $1,54 \pm 0,18$ \\
\hline Пентадекановая & & $\mathrm{C}_{11} \mathrm{H}_{29} \mathrm{COOH}$ & $1,03 \pm 0,04$ \\
\hline
\end{tabular}

Далее были установлены характеристики используемых сливок. На основании проведенных исследований по изучению качества сливок можно сделать вывод, что используемые нами сливки для производства сливочного масла методом сбивания отвечают всем требованиям, предъявляемым к сливкам при производстве сливочного масла.

Так как для производства всех образцов сливочного масла использовали одинаковое сырьё (сливки, полученные от одной партии молока), то разница в качестве выработанного продукта полностью будет зависеть от количества вносимого комплекса «ОмегаТрин», следовательно, по показателям сливочного масла можно судить о наиболее выгодном вносимого комплекса ПНЖК.
Данные проведенного эксперимента свидетельствуют о том, что ком-плекс «ОмегаТрин» не оказывает влияния на органолептические показатели сливочного масла, кроме незначительного изменения цвета от бледнобелого для контрольного образца до светложелтого равномерного по всей массе для опытных образцов.

По структуре сливочное масло представляет собой непрерывную жировую среду, состоящую из соединенных или собранных вместе мелких комочков жира, небольших капель воды или плазмы и пузырьков воздуха, причем связывающей массой является свободный жидкий жир. Распределение жидкого жира зависит от механической обработки, а количество жидкой части - от температуры и продолжительности ее воздействия. 
В готовом продукте также определяли массовую долю влаги, кислот-ность, термоустойчивость, температуры плавления и затвердевания молочного жира, кислотные числа. Массовая доля влаги играет важную роль в формировании потребительских показателей и качества продукта, соответственно ее необходимо рассматривать как один из важнейших компонентов сливочного масла. Установлено, что внесение комплекса «ОмегаТрин» позволяет увеличить массовую долю жира готового продукта, и соответственно, снизить массовую долю влаги в сливочном масле.

По термоустойчивости можно судить о консистенции сливочного мас-ла. Наименьшая термоустойчивость 0,90 у контрольного образца, наибольшая - 0,93 у образца №2.
Следовательно, образец №2 имеет лучшую консистенцию.

Температура плавления и отвердевания молочного жира для всех ис-следуемых образцов колеблется в пределах допустимых значений. При до-бавлении комплекса ПНЖК происходит увеличение температуры плавления на $3,4 \%$, что говорит о воздействии «ОмегаТрин» на эти показатели.

Основным исходным критерием качества молочного жира является его химический состав, который характеризуется количественным содержанием жирных кислот, определяемых газовой хроматографией.

Содержание жирнокислотного состава исследуемых образцов сливочного масла приведено в таблице 4.

Таблица 4 - Содержание жирных кислот в сливочном масле

\begin{tabular}{|c|c|c|c|}
\hline ЖК/№ образца & №1 & №2 & $\begin{array}{c}\text { Контрольный } \\
\text { образец }\end{array}$ \\
\hline \multicolumn{4}{|c|}{ Насыщенные кислоты в том числе: } \\
\hline Октановая (каприловая) С 8:0 & 1,13141 & 1,41919 & 1,1145 \\
\hline Декановая (каприновая) С 10:0 & 2,18837 & 2,21081 & 2,1798 \\
\hline Додекановая (лауриновая) С 12:0 & 4,01082 & 4,25069 & 3,99763 \\
\hline Тридекановая С13:0 & 0,12204 & 0,12385 & 0,11438 \\
\hline Тетрадекановая (миристиновая) С 14:0 & 12,54104 & 12,91454 & 12,54182 \\
\hline Пентадекановая С 15:0 & 0,58361 & 0,60983 & 0,59174 \\
\hline Гексадекановая (пальмитиновая) С 16:0 & 30,9318 & 30,74637 & 30,94037 \\
\hline Гептадекановая (маргариновая) С 17:0 & 0,40151 & 0,40643 & 0,40278 \\
\hline Октадекановая (стеариновая) С $18: 0$ & 10,82969 & 10,64723 & 10,92597 \\
\hline Эйкозановая (арахиновая) С20:0 & 0,27824 & 0,23814 & 0,243 \\
\hline Сумма $\sum$ & 63,02 & 63,57 & 63,05 \\
\hline Среднее НЖК & 6,30 & 6,36 & 6,31 \\
\hline \multicolumn{4}{|c|}{ Мононенасыщинные кислоты, в том числе: } \\
\hline Тетрадеценовая (миристолеиновая) С 14:1 & 1,29364 & 1,30015 & 1,27967 \\
\hline Гексадеценовая (пальмитолеиновая) С 16:1 & 2,55079 & 2,54111 & 2,53884 \\
\hline Гептадеценовая C 17:1 & 0,30028 & 0,30891 & 0,32195 \\
\hline Октадеценовая (олеиновая) С 18:1 & 29,13602 & 28,63858 & 29,11647 \\
\hline Сумма $\sum$ & 33,28 & 32,79 & 33,26 \\
\hline Среднее МНЖК & 8,32 & 8,20 & 8,31 \\
\hline \multicolumn{4}{|c|}{ Полиненасыщенные кислоты, в том числе: } \\
\hline Октадекадиеновая (линолевая) С 18:2 & 2,33562 & 2,56962 & 2,10162 \\
\hline Октадекатриеновая (линоленовая) С18:3 & 0,69051 & 1,15851 & 0,22251 \\
\hline Сумма $\sum$ & 3,03 & 3,73 & 2,32 \\
\hline Среднее ПНЖК & 1,51 & 1,86 & 1,16 \\
\hline$\omega-6: \omega-3$ & $3,4: 1$ & $2,2: 1$ & $9,4: 1$ \\
\hline
\end{tabular}

Из таблицы видно, больше всего в сливочном масле содержится мононенасыщенных жирных кислот. На их долю в контрольном образце приходится $63,05 \%$, а для иссле- дуемых образцов в среднем $63,30 \%$. Содержание насыщенных жирных кислот в контрольном образце составляет $33,26 \%$, а в опытных образцах сливочного масла $33,14 \%$. Наличие 
полиненасыщенных жирных кислот в контрольном образце 2,32\%.

По содержанию линоленовой кислоты наиболее приближен к опти-мальному образец №2 - 1,16\%. Рекомендуемое соотношение полиненасы-щенных кислот $\omega-6: \omega-3$ находится в образце №2 и составляет 2,2:1, что позволяет считать его продуктом со сбалансированным жирнокислотным составом.

Биологическая эффективность сливочного масла обогащенного ком-плексом «ОмегаТрин» увеличилась по сравнению с контрольным образцом $(0,18)$ для образца №1 на $33,33 \%$, для образца №2 на $61,11 \%$, это связано с наличием в комплексе сбалансированного количества полиненасыщенных жирных кислот.

В результате проведенных исследований можно сделать вывод, что обогащение сливок комплексом «ОмегаТрин» повышает выход готового продукта для образца №1 на $2,7 \%$, а для образца №2 на $8,1 \%$.

Срок годности сливочного масла определяли визуально по изменениям органолептических показателей (запах, цвет, консистенция и вкус) при температуре от +5 до $-3^{\circ} \mathrm{C}$, а также по изменению кислотного числа, в течение 31 дня, вначале через каждые 10 суток. На 30 -ые сутки начались изменения в органолептических показателях всех образцов.
По результатам серии проведенных исследований, можно сделать следующие выводы. Внесение комплекса «ОмегаТрин» увеличивает температуру плавления молочного жира на $3,4 \%$, немного повышает термоустойчивость сливочного масла на 0.03 , приводит в сбалансированное соотношение содержание полиненасыщенных жирных кислот, за счет чего происходит повышение биологической эффективности готового продукта, увеличивается выход продукции на $8,1 \%$. Для производства сливочного масла сбалансированного по содержанию полиненасыщенных жирных кислот рекомендуется использовать комплекс «ОмегаТрин» в количестве 1,560 г на 1 кг сливок. При переработке сливок с комплексом «ОмегаТрин» в количестве 1,560 г на 1 кг сырья консистенция продукта была однородной, пластичной, плотной, поверхность на срезе блестящая, сухая на вид, вкус чистый, с хорошо выраженным с привкусом пастеризации и сливочный, выделившаяся пахта - однородной жидкости без осадков и хлопьев, слабо-желтого цвета. Таким образом, полученный новый продукт можно отнести к функциональным продуктам питания, обеспечивающим организм человека ненасыщенными жирными кислотами.

\section{БИБЛИОГРАФИЯ}

Вышемирский, Ф.А. Современный ассортимент сливочного масла [текст] / Ф.А. Вышемирский, Е.В. Топникова//Журн. Сыроделие и маслоде-лие. - 2008. - №7. - C.12-14.

Горбатова К.К. Химия и физика молока.СПб.:ГИОРД, 2003.-288c.

Иванкин, А.Н., О качестве растительных и животных жиров [текст] / А.Н. Иванкин, И.М. Чернуха, Т.Г. Кузнецова // Журн. Масложировая про-мышленность. 2007. - №2. - C.8-11.

Зайцева, Л.В. Роль жирных кислот в питании человека и при производстве пищевых продуктов [текст] / Л.В. Зайцева // Журн. Масложировая промышленность. - 2010. - №5. - C.11-15.
Кричман, Е.С. Роль пищевых добавок в увеличении сроков годности масложировых продуктов [текст] / Е.С. Кричман // Журн. Масложировая промышленность. - 2007. - №3. - C.42-43.

Кузнецов, В.В. Справочник технолога молочного производства. Технология и рецептуры. Т.3 : СПб.: ГИОРД, 2003.-512c.

Технический регламент на молоко и молочную продукцию (Ф3 от 12.06.2008 №88). -Новосибирск: Сиб.унив.изд-во-125 с.

Web Site 1:

http://dabao.info/allantoin.htm

Web Site 2:

http://www.advertology.ru/article65627.htm

Web Site 3:

http://www.molreka.ru/ru/articles/.view/id/19 